\title{
Ion-Molecule Reactions in Mixtures of Trimethylaluminum and Methylamines
}

\author{
Stephan B. H. Bach* and Denise C. Parent \\ Chemistry Division/Code 6110, Naval Research Laboratory, Washington, D,C., USA
}

\begin{abstract}
The ion-molecule reactions of mixtures of trimethylaluminum and methylamines, to serve as a model system for group 13-15 semiconductor fabrication, were examined by using Fourier transform ion cyclotron resonance mass spectrometry. Sequential ion-molecule reactions leading to formation of multiple adducts were observed for each of the reactant mixtures investigated. Collision-induced dissociation was used to probe the adduct structures. There is evidence for hydrogen bonding between the amines and aluminum in most of the adducts studied. Rearrangement of the aluminum/nitrogen skeletons was not observed, although the aluminum/nitrogen bonds appear to be relatively strong, so that stable adducts can be formed. The monomethylanine and dimethylamine readily produce gas-phase neutral adducts with trimethylaluminum, which can be related to the basicities of the methylamines. (] Am Soc Mass Spectrom 1993, 4, 111-116)
\end{abstract}

$\mathrm{M}$ etalorganic chemical vapor deposition (MOCVD) is an outgrowth of metalorganic chemical vapor epitaxy (MOCVE) that finds its beginnings in the work of Manasevit [1]. This technology has shown rapid progress from the first demonstration of device-quality material to an emphasis on the devices themselves [2]. Little is understood, though, of the reactions that take the precursors from the gas phase to the formation of semiconductor devices on a surface.

This work is directed toward developing an understanding of the gas-phase interactions of the precursors utilized in the growth of group 13-15 semiconductor materials. These investigations also have the aim of suggesting possible new compounds that will reduce the impurities resulting from the incomplete decomposition of the precursors. This will involve identifying stable adduct species that could produce the desired semiconductor material with the degradation of a single precursor rather than using two or more precursors. A further goal is to investigate the role that ion-molecule reactions may play in determining the final composition of the materials that are incorporated into semiconductor devices. Ion-molecule reactions are most likely to be important in new MOCVD technolo-

"Present address: Division of Earth and Physical Sciences, University of Texas at San Antonio, San Antonio, TX 78249-0063.

Address reprint requests to Denise C. Parent, Chemistry Division/Code 6110, Naval Research Laboratory, Washington, D.C. $20375-5000$. gies, such as plasma-assisted MOCVD [3] and electron cyclotron resonance plasma-excited MOCVD [4], and in the laser-induced photochemistry [5] of MOCVD precursors used to initiate the reaction sequence that ultimately leads to the formation of the desired semiconductor material.

Interrante et al. [6] have shown that good quality aluminum nitride films can be produced in a chemical vapor deposition (CVD) reactor by using $\left(\left(\mathrm{CH}_{3}\right)_{2} \mathrm{AlNH}_{2}\right)_{3}$, which is obtained by reacting trimethylaluminum (TMAl) and ammonia, and have identified the gas-phase products that occur during deposition. This group is also synthesizing other cyclic dialkylaluminum amides $\left(\mathbf{R}_{2} \mathrm{AlNH}_{2}\right)_{n}$ as precursors for high-purity AIN powder and thin films, as well as investigating the solution kinetics [7].

In our laboratory we have recently investigated [8] the fragmentation of TMAl and the ion chemistry in mixtures of TMAl and ammonia. The aluminum/ ammonia adduct $\left(\mathrm{CH}_{3}\right)_{2} \mathrm{AlNH}_{3}^{+}$and the diammonia adduct $\left(\mathrm{CH}_{3}\right)_{2} \mathrm{Al}\left(\mathrm{NH}_{3}\right)_{2}^{+}$were both observed. In extending this work, we hoped that the study of the gas-phase mixtures of methylamines and TMAl would provide insights into the gas-phase chemistry occurring among the group 13-15 precursors. Thus, TMAI serves as a model for other group 13 precursors (i.e., trimethylindium and trimethylgallium), whereas the methylamines can be considered as analogs to other group 15 precursors, such as those containing phosphorus and arsenic. 


\section{Experimental}

The experiments were performed with a Fourier transform ion cyclotron resonance mass spectrometer, which has been described in detail elsewhere [9]. The experimental apparatus consists of a Nicolet FTMS-1000 data system (EXTREL-FTMS, Madison, WI), a 3-T superconducting magnet, and a custom vacuum system with a $1 \times 1 \times 2$ ( $z$ axis)-in. cell made of stainless steel, except for the trapping plates, which are composed of $90 \%$ transparent nickel mesh.

The TMAl and methylamines were introduced into the vacuum chamber via leak valves and maintained at static pressures between 1.0 and $2.0 \times 10^{-8}$ torr for TMAl and between $2.0 \times 10^{-8}$ and $1.0 \times 10^{-7}$ torr for the methylamines. (All pressures reported are uncorrected for instrumental factors and ionization gauge response.) The TMAl samples were prepared by transferring small quantities from the shipping container into a sample container and performing several freeze/pump/thaw cycles to remove noncondensible gases. The methylamine samples were used without further purification. The purities of all samples were verified by their electron ionization (EI) mass spectra.

All of the ion-molecule reactions to be discussed were studied by isolating the reactant ion, using MS $^{n}$ (tandem mass spectrometry) techniques, and varying the reaction time. Absolute or even relative rate constants were not determined, however, because the pressures of the various gases could not be calibrated. Two factors precluded accurate pressure calibrations: first, limited literature data on ion-molecule reactions with $\mathrm{TMAl}$; second, difficulty in maintaining stable pressures of most of these compounds owing to their "stickiness."

The collision-induced dissociation (CID) experiments were carried out by applying a single frequency pulse $(0.06-3.0-\mathrm{ms}$ duration) to translationally excite the ion of interest, which undergoes subsequent collisions with either the reactant gases already present or with added argon. The pressure of argon was varied between $2.0 \times 10^{-8}$ and $1.0 \times 10^{-7}$ torr.

\section{Results and Discussion}

\section{Evidence for Neutral-Neutral Reactions}

The base peak in the EI mass spectrum of a mixture of TMAl and monomethylamine (MMAm) or dimethylamine (DMAm) is the adduct $\left(\mathrm{CH}_{3}\right)_{2} \mathrm{AlNH}_{2} \mathrm{CH}_{3}^{+}$or $\left(\mathrm{CH}_{3}\right)_{2} \mathrm{AlNH}\left(\mathrm{CH}_{3}\right)_{2}^{+}$, respectively. These products appear immediately after ionization, with no subsequent reaction time, and are apparently due to neutral-neutral reactions of TMAl with the methylamines. The methyl group can be lost during the reaction or on ionization. The parent adduct was carefully searched for but not observed, suggesting either that the methyl is lost during adduct formation or that the parent ion is unstable. The results of the ion- molecule reactions suggest the latter explanation is correct. In a previous study of the ion chemistry of $\left(\mathrm{CH}_{3}\right)_{3} \mathrm{Al}{ }^{\prime}$, Kappes et al. [10] mentioned that neutral complexes were formed between TMAl and various neutrals including trimethylamine (TMAm); however, they did not indicate whether the parent ion of the neutral complex was actually detected. The strength of the neutral interaction appears to be correlated to the $\mathrm{pK}_{\mathrm{b}}$ 's of the amines, which are $4.74\left(\mathrm{NH}_{3}\right), 3.36$ $\left(\mathrm{NH}_{2} \mathrm{CH}_{3}\right), 3.29\left(\mathrm{NH}\left(\mathrm{CH}_{3}\right)_{2}\right)$, and $4.28\left(\mathrm{~N}\left(\mathrm{CH}_{3}\right)_{3}\right)[11]$. In this work, the two methylamines that were observed to form neutral adducts are also the strongest bases. Because the Al center in TMAl has no electrons available for bonding, the methylamine must supply the electrons. The ability to donate electrons is one measure of basicity, thus the correlation with $\mathrm{pK}_{\mathrm{b}}$ is to be expected.

These adduct ions are ejected when the reactant ion [i.e., $\left(\mathrm{CH}_{3}\right)_{2} \mathrm{Al}^{+}$or the amine parent ion] is mass selected. Any neutral-neutral reaction products are not detected, because there is no other ionization event. The observation of the adduct ions arising from neutral-neutral reactions, although interesting, is independent of the ion-molecule chemistry to be discussed in the rest of this report.

\section{Ion-Molecule Reactions}

The generalized ion-molecule reaction scheme for mixtures of TMAl with MMAm, DMAm, or TMAm is depicted in Figure 1. (The numbers above the arrows refer to the reaction numbers in the following discussion.) For each amine, the primary ionic product is the aluminum/amine adduct $\left(\mathrm{CH}_{3}\right)_{2} \mathrm{AlNH}_{x}$ $\left(\mathrm{CH}_{3}\right)_{3-x}^{+}$(where $x=2,1$, and 0 for MMAm, DMAm, and TMAm, respectively), $\equiv[D M A] \cdot A]^{+}$(DMAl is dimethylaluminum, and $\Lambda$ is the amine). One observed pathway for the formation of this product is the reac-

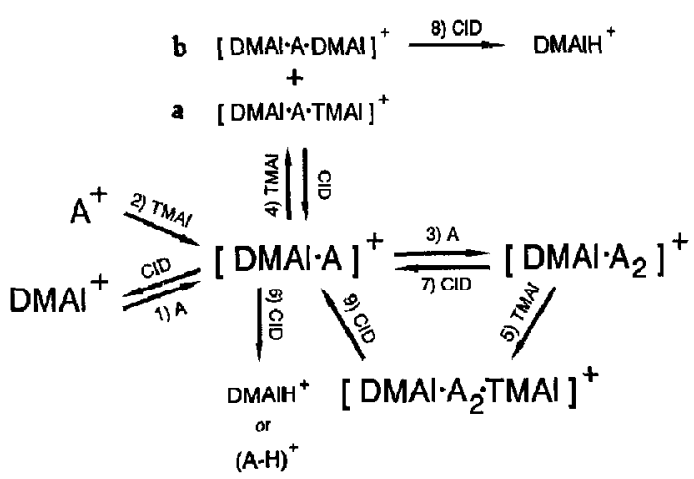

Figure 1. A yencralized schematic of the ion-molecule reactions observed in mixtures of TMAl with different amines $(A)$, as well as the results of the CID experiments. Numbers above the arrows refer to the reactions in the text. Reaction 4 was not observed with TMAm, nor was reaction $4 \mathrm{~b}$ with MMAm. 
tion of $\mathrm{DMAl}^{+}$with the neutral amine as follows:

$$
\begin{aligned}
& \left(\mathrm{CH}_{3}\right)_{2} \mathrm{Al}^{+}+\mathrm{NH}_{x}\left(\mathrm{CH}_{3}\right)_{3-x} \\
& \rightarrow\left(\mathrm{CH}_{3}\right)_{2} \mathrm{AlNH}_{x}\left(\mathrm{CH}_{3}\right)_{3-x}^{+}
\end{aligned}
$$

A second pathway that was also observed is

$$
\begin{aligned}
\mathrm{NH}_{x} & \left(\mathrm{CH}_{3}\right)_{3-x}^{+}+\left(\mathrm{CHI}_{3}\right)_{3} \mathrm{Al} \\
& \rightarrow\left(\mathrm{CH}_{3}\right)_{2} \mathrm{AlNH}_{x}\left(\mathrm{CH}_{3}\right)_{3-x}^{+}+\mathrm{CH}_{3}
\end{aligned}
$$

Because this adduct product is also observed with ammonia, the methyl is presumably lost from the TMA1 moiety. This does not preclude the loss of methyl from the amine in these reactions, however. One would expect reaction 1 to be more rapid than reaction 2 , owing to steric hinderance in the interaction between neutral TMAl and the methylamine cation, which must pass through an intermediate with a fourfold coordinate $\mathrm{Al}$ center. The reaction of $\mathrm{DMAl}^{+}$and the neutral methylamine can simply form the adduct without any rearrangement necessary. The relative rates could not be experimentally verified, however, because we could not calibrate the pressures of all of the compounds used, as noted previously.

The $[D M A l \cdot A]^{+}$adducts undergo a second addition reaction with the neutral amine to yield the diamine adduct $\left(\mathrm{CH}_{3}\right)_{2} \mathrm{Al}\left(\mathrm{NH}_{x}\left(\mathrm{CH}_{3}\right)_{3-x}\right)_{2}^{+} \equiv[\mathrm{DMAl}$. $\mathrm{A}_{2} \mathrm{l}^{+}$, as shown in reaction 3 ;

$$
\begin{gathered}
\left(\mathrm{CH}_{3}\right)_{2} \mathrm{AlNH}_{x}\left(\mathrm{CH}_{3}\right)_{3-x}^{+}+\mathrm{NH}_{x}\left(\mathrm{CH}_{3}\right)_{3-x} \\
\rightarrow\left(\mathrm{CH}_{3}\right)_{2} \mathrm{Al}\left(\mathrm{NH}_{x}\left(\mathrm{CH}_{3}\right)_{3-x}\right)_{2}^{+}
\end{gathered}
$$

Reactions 1 and 3 were also observed in an older study [10] of $\mathrm{DMAl}^{+}$reacting with TMAm.

With the exception of TMAm, the aluminum/amine adduct $[\mathrm{DMAl} \cdot \mathrm{A}]^{+}$also reacts with $\mathrm{TMAl}$ to form a dialuminum adduct, $\left(\mathrm{CH}_{3}\right)_{2} \mathrm{AlNH}_{x}\left(\mathrm{CH}_{3}\right)_{3-x}$ $\mathrm{Al}\left(\mathrm{CH}_{3}\right)_{3}^{+} \equiv[\mathrm{DMAl} \cdot \mathrm{A} \cdot \mathrm{TMAl}]^{+}$, as follows:

$$
\begin{aligned}
& \left(\mathrm{CH}_{3}\right)_{2} \mathrm{AlNH}_{x}\left(\mathrm{CH}_{3}\right)_{3-x}^{+}+\mathrm{Al}\left(\mathrm{CH}_{3}\right)_{3} \\
& \rightarrow\left(\mathrm{CH}_{3}\right)_{2} \mathrm{AlNH}_{x}\left(\mathrm{CH}_{3}\right)_{3-x} \mathrm{Al}\left(\mathrm{CH}_{3}\right)_{3}^{+}
\end{aligned}
$$

The nonreactivity of TMAm in this reaction could be due to experimental factors (i.e., the relative pressures of TMAl and TMAm were such that reaction $4 \mathrm{a}$ was not competitive with reaction 3). With DMAm, an additional product $\left(\mathrm{CH}_{3}\right)_{2} \mathrm{AlNH}{ }_{x}\left(\mathrm{CH}_{3}\right)_{3-x} \mathrm{Al}$ $\left(\mathrm{CH}_{3}\right)_{2}^{+} \equiv[\mathrm{DMAl} \cdot \mathrm{A} \cdot \mathrm{DMAl}]^{+}$was also observed:

$$
\begin{aligned}
& \left(\mathrm{CH}_{3}\right)_{2} \mathrm{AlNH}_{x}\left(\mathrm{CII}_{3}\right)_{3-x}^{+}+\mathrm{Al}\left(\mathrm{CH}_{3}\right)_{3} \\
& \quad \rightarrow\left(\mathrm{CH}_{3}\right)_{2} \mathrm{AlNH}_{x}\left(\mathrm{CH}_{3}\right)_{3-x} \mathrm{Al}\left(\mathrm{CH}_{3}\right)_{2}^{+}+\mathrm{CH}_{3}
\end{aligned}
$$

corresponding to methyl loss from the dialuminum adduct formed in reaction 4a. This methyl loss product was more intense than the adduct formed in reaction $4 a$. It is also the only reaction, in addition to reaction 2 , where neutral loss was observed.

The diamine adducts $\left[\mathrm{DMAl} \cdot \mathrm{A}_{2}\right]^{+}$formed in reaction 3 reacted further with TMAl via reaction 5 ,

$$
\begin{aligned}
& \left(\mathrm{CH}_{3}\right)_{2} \mathrm{Al}\left(\mathrm{NH}_{x}\left(\mathrm{CH}_{3}\right)_{3-x}\right)_{2}^{+}+\operatorname{Al}\left(\mathrm{CH}_{3}\right)_{3} \\
& \rightarrow\left(\mathrm{CH}_{3}\right)_{2} \mathrm{Al}\left(\mathrm{NH}_{x}\left(\mathrm{CH}_{3}\right)_{3-x}\right)_{2} \mathrm{Al}\left(\mathrm{CH}_{3}\right)_{3}^{+}
\end{aligned}
$$

to produce a diamine/dialuminum adduct $\left(\mathrm{CH}_{3}\right)_{2} \mathrm{Al}$ $\left(\mathrm{NH}_{x}\left(\mathrm{CH}_{3}\right)_{3-x}\right)_{2} \mathrm{Al}\left(\mathrm{CH}_{3}\right)_{3}^{+} \equiv\left[\mathrm{DMAl} \cdot \mathrm{A}_{2} \cdot \mathrm{TMAl}\right]^{+}$.

The ion adducts, because they undergo no fragmentation, contain excess energy equal to the bond strength of the new bond(s) [12]. ${ }^{2}$ The disposal of this energy can take several forms: It can be emitted in the form of infrared photons; it can be accommodated by the product in its internal modes; or it can be removed by thermalizing collisions. These adducts have a large number of internal degrees of freedom $(3 n-3=45$ for the smallest adduct), many of which will be lowfrequency bending modes. This will lead to long lifetimes for the adduct ions. The observation of adduct ions between $\mathrm{DMAl}^{+}$and the methylamines is not surprising when compared with previous work in Fourier transform mass spectrometry (FTMS). We have observed adduct formation to occur relatively efficiently when the neutral reagent has a permanent dipole moment [9], as is the case for the methylamines.

Methyl loss on adduct formation is only observed when TMAl is one of the reactants. Reactions 2 and $4 \mathrm{~b}$ are examples of ion-molecule reactions where methyl loss is observed. The major exception is reaction 5 . where TMAl is seen to complex without methyl loss. This suggests that geometric factors are important in determining the stability of these adducts, at least for the smaller adducts.

\section{Structures of Neutral Complexes of Alumintum Compounds}

Before beginning a discussion of the CID results and what they imply about the adduct ion structure, it is useful to review what is known about neutral adducts of aluminum compounds, such as TMAl and $\mathrm{AlX}_{3}$ (where $X$ is a halogen), with various other molecules. Most of the structural information comes from gasphase electron diffraction studies [13]. Generally, the aluminum compound/neutral adduct can be described as an electron pair donor/acceptor complex, with the neutral containing an electron-rich atom, such as $\mathrm{N}, \mathrm{P}$, $\mathrm{O}$, or $\mathrm{S}$, which then forms a dative bond to the $\mathrm{Al}$ atom by donating electrons into an empty orbital on the

${ }^{1}$ For the reaction of TMAl with TMAm the $\Delta H_{\mathrm{f}}(\mathrm{g})$ of the adduct $\left(\mathrm{CH}_{3}\right)_{3} \mathrm{AlN}\left(\mathrm{CH}_{3}\right)_{3}$ was determined to be $-30.69 \mathrm{kcal} / \mathrm{mol}$, which gives an indication of the magnitude of this excess energy. 
aluminum. This bond is weaker than a normal covalent bond. In these complexes the aluminum is fourfold coordinate, giving it a formal negative charge, whereas the donor atom has lost electron density, giving it a formal positive charge. The donor atom also has a coordinate number that is one greater than it has in the isolated neutral (i.e., four for nitrogen).

There are several adducts that do not fit this picture, however. The dimers of TMAl and DMAlH have bridging methyl or hydrogen groups, respectively, and some degree of Al-Al bonding [13]. Thus, the aluminum atoms in these complexes are fivefold coordinate. Hydrogen bonding is also observed in the complex of TMAl with $\mathrm{BH}_{3}$ [13]. $\mathrm{AlH}_{3}$ is found to complex twice with TMAm, forming a trigonal bipyramid in which the aluminum is also fivefold coordinate [14].

Another class of aluminum compounds are those having the composition $R_{2}$ AlY, where $Y$ is a halogen atom or radical such as $\mathrm{OR}, \mathrm{SR}$, or $\mathrm{NR}_{2}$. (These compounds differ from those preceding in that the two constituents are no longer stable, free molecules.) The aluminum is bonded to two carbon (or hydrogen) atoms and the electron donor atom and hence is threefold coordinated. In the gas phase these compounds form cyclic oligomers, with a ring consisting of alternating donor atoms and fourfold coordinated aluminum atoms. The ring bonds are all equivalent, suggesting a resonance between covalent and donoracceptor bonds [13].

\section{Collision-Induced Dissociation of Adduct Ions}

Most of the adduct product ions were produced in sufficient quantities for CID studies to glean information about their structures. The aluminum/amine adducts [DMAl $\cdot \mathrm{A}]^{+}$formed by all three methylamines yield the fragment ions $\mathrm{DMAl}^{+}, \mathrm{MMAl}^{+}$, and $\mathrm{Al}^{+}$on $\mathrm{CID}$. The amine cation $\mathrm{A}^{+}$was never observed, which imposes an upper limit of $7.82 \mathrm{eV}$ [the ionization potential (IP) of TMAm] on the IP of DMAI. In addition, the aluminum/amine adducts also undergo the following fragmentation process:

or

$$
\begin{aligned}
\left(\mathrm{CH}_{3}\right)_{2} \mathrm{AlNH}_{x}\left(\mathrm{CH}_{3}\right)_{3-x}^{+} & \\
& \rightarrow\left(\mathrm{CH}_{3}\right)_{2} \mathrm{AlH}+\mathrm{NH}_{x-1}\left(\mathrm{CH}_{3}\right)_{3-x}^{+} \\
& \rightarrow\left(\mathrm{CH}_{3}\right)_{2} \mathrm{AlH}^{+}+\mathrm{NH}_{x}{ }_{2}\left(\mathrm{CH}_{3}\right)_{3-x}
\end{aligned}
$$

With MMAm, the ionic product is $\left(\mathrm{CH}_{3}\right)_{2} \mathrm{AlH}^{+} \equiv$ $\mathrm{DMAlH}^{+}$, whereas with DMAm and TMAm, the ionic product is $(\mathrm{A}-\mathrm{H})^{+}, \mathrm{N}\left(\mathrm{CH}_{3}\right)_{2}^{+}$, or $\left(\mathrm{CH}_{3}\right)_{2} \mathrm{NCH}_{2}^{+}$, respectively. [For TMAm, the two DMAlH ${ }^{+}$and $(\mathrm{A}-\mathrm{H})^{+}$products have the same nominal mass. The resolution of the FTMS is sufficient to allow the two products to be differentiated.] Note that this result allows us to bracket the unknown IP of $\left(\mathrm{CH}_{3}\right)_{2} \mathrm{AlH}$ between $6.7 \mathrm{eV}$ (the IP of $\mathrm{HNCH}_{3}$ ) and $5.7 \mathrm{eV}$ [the $\mathrm{IP}$ of $\left(\mathrm{CH}_{3}\right)_{2} \mathrm{NCH}_{2}$.
The products of reaction 6 suggest that the aluminum/amine adduct has a bridging hydrogen atom structure, that is, a $\mathrm{C}_{2}-\mathrm{Al}-\mathrm{H}-\mathrm{N}$ skeleton and not the $\mathrm{C}_{2}-\mathrm{Al}-\mathrm{N}$ skeleton that might be expected from the preceding discussion of neutral adduct structure. (Note that this structure is not likely for T'MAm, as discussed in more detail later.)

Collision-induced dissociation of the diamine adducts regenerates the $[\mathrm{DMAl} \cdot \mathrm{A}]^{+}$adduct for all three methylamines.

$$
\begin{array}{rl}
\left(\mathrm{CH}_{3}\right)_{2} & \mathrm{Al}\left(\mathrm{NH}_{x}\left(\mathrm{CH}_{3}\right)_{3-x}\right)_{2}^{+} \\
\rightarrow & \left(\mathrm{CH}_{3}\right)_{2} \mathrm{AlNH}_{x}\left(\mathrm{CH}_{3}\right)_{3-x}^{+} \\
& +\mathrm{NH}_{x}\left(\mathrm{CH}_{3}\right)_{3-x}
\end{array}
$$

in addition to produring the sther fragment ions observed in CID of [DMAl $\cdot \mathrm{A}]^{+}$. The diamine adduct is most likely formed by the methylamine "attacking" the positive aluminum center, forcing the three groups attached to the aluminum out of the $\mathrm{C}_{2}-\mathrm{Al}-\mathrm{X}$ plane to form a tetrahedral complex analogous to that reported by Anderson et al. [12] for the neutral complex of TMAl with TMAm (to cite one example). Similar geometric changes have been observed in matrix isolation studies by Piocos and Ault [15] of the neutral complex of trimethylgallium and arsine.

The dialuminum adduct $[\mathrm{DMAl} \cdot \mathrm{A} \cdot \mathrm{DMAl}]^{+}$, produced by reaction $4 \mathrm{~b}$ in the DMAm system, yields predominantly $\mathrm{DMAlH}^{+}$on CID:

$$
\begin{aligned}
& \left(\mathrm{CH}_{3}\right)_{2} \mathrm{AlNH}\left(\mathrm{CH}_{3}\right)_{2} \mathrm{Al}\left(\mathrm{CH}_{3}\right)_{2}^{+} \\
& \rightarrow \operatorname{Al}\left(\mathrm{CH}_{3}\right)_{2} \mathrm{H}^{+}+\left(\mathrm{CH}_{3}\right)_{2} \mathrm{AlN}\left(\mathrm{CH}_{3}\right)_{2}
\end{aligned}
$$

Observation of this product also suggests that the aluminum/amine adduct is hydrogen bonded, with the second DMAl bonded to the nitrogen. The CID process presumably involves loss of a neutral aluminum/amine adduct, which implies that the Al-N and $\mathrm{Al}-\mathrm{H}$ bonds are stronger than the $\mathrm{N}-\mathrm{H}$ bond. It is interesting to note that although a second TMA1 adds to the nitrogen as in reaction 4 , a second amine adds to the aluminum. Thus, Al- $\mathrm{N}$ bond formation is favored over $\mathrm{Al}-\mathrm{Al}$ and $\mathrm{N}-\mathrm{N}$ bond formation, which again indicates a strong $\mathrm{Nl}-\mathrm{N}$ bond.

Alternative structures for the adducts formed by reactions 1 or 2 and $4 \mathrm{~b}$ can be considered. If the [DMAl $-\mathrm{A}^{+}$adduct is conventionally bonded, with a $\mathrm{C}_{2}-\mathrm{Al}-\mathrm{N}$ skeleton, then reaction 6 involves transfer of a hydrogen from the amine to DMAl during the CID process. Addilion of a second DMAl to the [DMAl . $\mathrm{Al}^{+}$adduct (reaction $4 \mathrm{~b}$ ) would be at the aluminum and not at the nitrogen, which is already fourfold coordinate. Reaction 8 would also involve transfer of hydrogen from the amine to the aluminum. This scenario seems less likely than the hydrogen-bonded structure with direct bond cleavage. 
The most interesting CID process is that of the dialuminum/diamine adducts [DMAl $\cdot \mathrm{A}_{2} \cdot \mathrm{TMAl}^{+}$, which in each case regenerate [DMAl $\cdot \mathrm{A}]^{+}$,

$$
\begin{gathered}
\left(\mathrm{CH}_{3}\right)_{2} \mathrm{Al}\left(\mathrm{NH}_{x}\left(\mathrm{CH}_{3}\right)_{3-x}\right)_{2} \mathrm{Al}\left(\mathrm{CH}_{3}\right)_{3}^{+} \\
\rightarrow\left(\mathrm{CH}_{3}\right)_{2} \mathrm{AlNH}_{x}\left(\mathrm{CH}_{3}\right)_{3-x}^{+} \\
+\left(\mathrm{CH}_{3}\right)_{3} \mathrm{AlNH}_{x}\left(\mathrm{CH}_{3}\right)_{3-x}
\end{gathered}
$$

by losing a stable aluminum/amine neutral adduct. Loss of a single amine or aluminum moiety was not observed, even at the lowest CID energies; however, these dialuminum/diamine adducts represent two very different cases. With MMAm or DMAm one can postulate the following reaction sequence: The aluminum/amine adduct is hydrogen bonded; the second amine coordinates to the aluminum center; and the second TMAl coordinates to the first amine at the nitrogen center, giving an ion with the structure shown in Structure 1. The CID process involves cleavage of the $\mathrm{Al}-\mathrm{H}$ bond. The addition of the second amine probably does not involve hydrogen bonding, because one would then expect to also see fragmentation into dialuminum/amine adduct plus amine products.

The picture becomes less clear when considering the case of TMAm. This amine has no acidic hydrogens, in contrast to MMAm or DMAm. The aluminum/amine adduct presumably has a $\mathrm{C}_{2}-\mathrm{Al}-\mathrm{N}$ skeleton, and the second amine can coordinate to the aluminum center. The difficulty arises when considering the point of attachment of the second TMAl. Both nitrogens and the aluminum are already fourfold coordinate. Attack of the TMAl at one of the nitrogen centers, to form a linear or cyclic $\mathrm{N}-\mathrm{Al}-\mathrm{N}-\mathrm{Al}$ backbone, rather than at the aluminum center, which would produce a branched (N) $-\mathrm{Al}-\mathrm{Al}$ structure, is consistent with the primary CID fragment being the aluminum/amine adduct. If

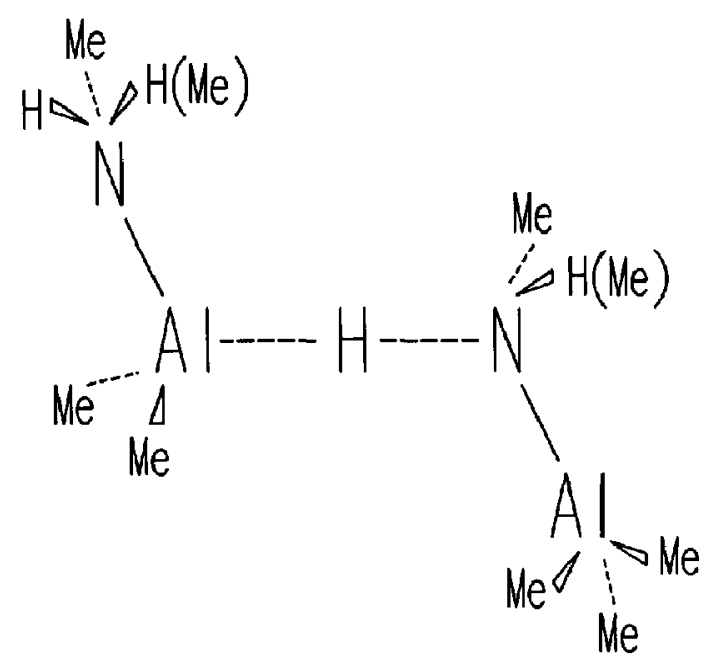

Structure 1

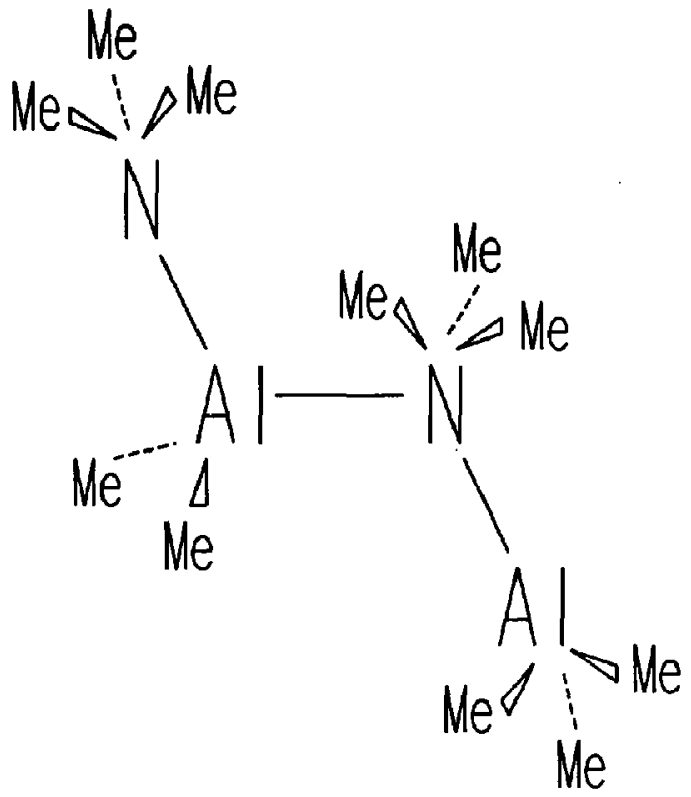

Structure 2

attachment occurred at the aluminum, one would expect to preferentially lose a single moiety (an amine or TMAl, requiring cleavage of one bond) instead of losing an adduct (requiring cleavage of two bonds). The postulated structure (Structure 2) has a fivefold coordinated nitrogen. This is rather surprising, because fivefold coordinated nitrogens are unknown, whereas several examples of fivefold coordinated aluminums have been found [13]; however, this is the only structure consistent with the CID results.

\section{Summary}

We have observed many reactions between the MOCVD precursors examined in this study. Adducts due to neutral reactions occurring on mixing of the precursors were observed by EI ionization. The neutral adducts $\left(\mathrm{CH}_{3}\right)_{3} \mathrm{AlNH}_{2} \mathrm{CH}_{3}$ and $\left(\mathrm{CH}_{3}\right)_{3} \mathrm{AlNH}\left(\mathrm{CH}_{3}\right)_{2}$ are possibly stable enough that they could be produced in macroscopic quantities. These products are similar to the adduct aluminum precursor $\mathrm{H}_{3} \mathrm{AlN}\left(\mathrm{CH}_{3}\right)_{3}$, which is commercially available (American Cyanamid Co., Wayne, NJ).

The strength of interaction of the neutral adducts is postulated to closely follow the basicity of the methylamines, MMAm $\approx$ DMAm $>$ TMAm $\approx \mathrm{NH}_{3}$. The two methylamines that readily form the neutral adduct are also the two strongest bases. Ammonia and TMAm were not observed to form neutral adducts in our work.

The reactions between $\mathrm{DMAl}^{+}$and the methylamines, as well as ammonia [8], result in the formation of a variety of adducts that contain up to four compo- 
nents. Under CID, most of the adducts simply regenerated the initial reactants. Evidence for hydrogen bonding in the initial DMAl/amine adduct was observed. This leads us to conclude that the adducts produced are simply acid/base pairs and that the strength of interaction depends mostly on the relative acidity and basicity of the reaction partners. In some cases, the $\mathrm{Al}-\mathrm{N}$ bond that is formed can be relatively strong, although methyl loss is not usually observed. For example, the dialuminum/diamine adducts appear to lose a stable $[\mathrm{TMA} \cdot \mathrm{A}]$ neutral on CID.

From this work and other similar studies it becomes apparent how little is known about the gas-phase chemistry of the MOCVD precursors and how great the impact of that chemistry can be. The observation of the neutral gas-phase adducts and the ready formation of ion-molecule adducts shows that these types of species are relevant when considering the likely pathways for the incorporation of unwanted impurities. The gas-phase stability of the adducts hints that these species may also be more stable on the deposition surface than previously thought and therefore would be a problem in the production of high-quality materials for solid-state devices.

\section{Acknowledgments}

We thank Herb Nelson for his interest and support during this project. This work was funded by the Office of Naval Research.

\section{References}

1. Manasevit, H. M. Appl. Phys. Lett. 1968, 12, 156-159.

2. DeBaars, S. P.; Maa, B. Y.; Dapkus, P. D.; Danner, A. D.; Lee, H. C. I. Crystal Growth 1986, 77, 188-193.

3. Heinecke, H.; Brauers, A.; Lüth, H.; Balk, P. J. Crystal Growth $1986,77,241-249$.

4. Zembusto, S.; Sasaki, T. I. Crystal Growth 1986, 77, 250-256.

5. (a) Zhang, Y.; Stuke, M. I. Crystal Growth 1988, 93, 143-150. (b) Horwitz, J. S.; Villa, E.; Hsu, D. S. Y. J. Phys. Chem. 1990. 94, 7214-7219.

6. (a) Interrante, L. V.; Lee, W.; McConnell, M.; Lewis, N.; Hall, E. J. Electrochem. Soc. 1989, 136, 472; (b) Sauls, F. C.; Interrante, L. V.; Jiang, Z. Inorg. Chem. 1990, 29, 2989; (c) Amato, C. C.; Hudson, J. B.; Interrante, L. V. Appl. Surf. Sci. 1992, 54, 18.

7. Interrante, L. V.; Sigel, G. A.; Garbauskas, M.; Hejna, C.; Slack, G. A. Inorg. Chem. 1989, 28, 252.

8. Bach, S. B. H.; McElvany, S. W. Organometallics, to be submitted.

9. Parent, D. C.; McElvany, S. W. I. Am. Chem. Soc. 1989, 111, 2393-2401.

10. Kappes, M. M.; Uppal, J. S.; Staley, R. H. Organometallics $1982,1,1303$.

11. Huheey, J. E. Inorganic Chemistry: Principles of Structure and Reactivity; Harper \& Row: New York, 1978; Chapter 7.

12. Anderson, G. A.; Forgaard, F. R.; Haaland, A. Acta Chem. Scand. 1972, 26, 1947.

13. Haaland, A. In Stereochemical Applications of Gas-Phase Electron Diffraction, Part B; Hargittai, I.; Hargittai M., Eds., VCH Publishers, Inc.: New York, 1988; Chapter 8.

14. Mastryukov, V. S; Golubinskii, A. V; Vilkov, L. V. Zh. Strukt. Khim. 1979, 20, 921. (English translation: I. Struct. Chem. USSR, 1979, 20, 788.)

15. Piocos, E. A.; Ault, B. S. J. Phys. Chem. 1991, 95, 6827. 